\title{
Analysis of the hygroscopic and volatile properties of ammonium sulphate seeded and unseeded SOA particles
}

\author{
N. K. Meyer 1,* , J. Duplissy ${ }^{2}$, M. Gysel ${ }^{2}$, A. Metzger $^{2}$, J. Dommen ${ }^{2}$, E. Weingartner ${ }^{2}$, M. R. Alfarra ${ }^{2}$, A. S. H. Prevot ${ }^{2}$, \\ C. Fletcher ${ }^{1}$, N. Good ${ }^{3}$, G. McFiggans ${ }^{3}$, ${ }^{\circ}$ A. M. Jonsson ${ }^{4}$, M. Hallquist ${ }^{4}$, U. Baltensperger ${ }^{2}$, and Z. D. Ristovski ${ }^{1}$ \\ ${ }^{1}$ International Laboratory for Air Quality and Health, Queensland University of Technology, Brisbane QLD 4000, Australia \\ ${ }^{2}$ Laboratory of Atmospheric Chemistry, Paul Scherrer Institut, 5232 Villigen PSI, Switzerland \\ ${ }^{3}$ Centre for Atmospheric Sciences, School of Earth, Atmospheric and Environmental Sciences, University of Manchester, \\ Manchester, M60 1QD, UK \\ ${ }^{4}$ Department of Chemistry, Atmospheric Science, University of Gothenburg, 41296 Gothenburg, Sweden \\ * now at: IAST, FHNW University of Applied Sciences, Windisch 5210, Switzerland
}

Received: 28 March 2008 - Published in Atmos. Chem. Phys. Discuss.: 13 May 2008

Revised: 8 October 2008 - Accepted: 18 December 2008 - Published: 28 January 2009

\begin{abstract}
The volatile and hygroscopic properties of ammonium sulphate seeded and unseeded secondary organic aerosol (SOA) derived from the photo-oxidation of atmospherically relevant concentrations of $\alpha$-pinene were studied. The seed particles were electrospray generated ammonium sulphate $\left((\mathrm{NH} 4)_{2} \mathrm{SO}_{4}\right)$ having diameters of approximately $33 \mathrm{~nm}$ with a quasi-mono-disperse size distribution (geometric standard deviation $\sigma_{g}=1.3$ ). The volatile and hygroscopic properties of both seeded and unseeded SOA were simultaneously measured with a VH-TDMA (volatility - hygroscopicity tandem differential mobility analyzer). VH-TDMA measurements of unseeded SOA show a decrease in the hygroscopic growth (HGF) factor for increased volatilisation temperatures such that the more volatile compounds appear to be more hygroscopic. This is opposite to the expected preferential evaporation of more volatile but less hygroscopic material, but could also be due to enhanced oligomerisation occurring at the higher temperature in the thermodenuder. In addition, HGF measurements of seeded SOA were measured as a function of time at two relative humidities, below (RH 75\%) and above (RH 85\%) the deliquescence relative humidity (DRH) of the pure ammonium sulphate seeds. As these measurements were conducted during the onset phase of photo-oxidation, during particle growth, they enabled us to find the dependence of the HGF as a function of the volume fraction of the SOA coating. HGF's measured at RH of $85 \%$ showed a continuous decrease as the SOA coating thickness increased. The measured growth factors show good agree-
\end{abstract}

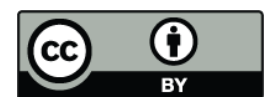

Correspondence to: Z. D. Ristovski (z.ristovski@qut.edu.au) ments with ZSR predictions indicating that, at these $\mathrm{RH}$ values, there are only minor solute-solute interactions. At $75 \%$ $\mathrm{RH}$, as the SOA fraction increased, a rapid increase in the HGF was observed indicating that an increasing fraction of the $\left(\mathrm{NH}_{4}\right)_{2} \mathrm{SO}_{4}$ is subject to a phase transition, going into solution, with an increasing volume fraction of SOA. To our knowledge this is the first time that SOA derived from photooxidised $\alpha$-pinene has been shown to affect the equilibrium water content of inorganic aerosols below their DRH. For SOA volume fractions above $\sim 0.3$ the measured growth factor followed roughly parallel to the ZSR prediction based on fully dissolved $\left(\mathrm{NH}_{4}\right)_{2} \mathrm{SO}_{4}$ although with a small difference that was just larger than the error estimate. Both incomplete dissolution and negative solute-solute interactions could be responsible for the lower HGF observed compared to the ZSR predictions.

\section{Introduction}

The atmospheric aerosol is the assembly of liquid or solid particles which are suspended in the gaseous phase of our atmosphere. This aerosol consists of a mixture of organic and inorganic substances. Organic matter contributes $20 \%$ to $60 \%$ of the mass of fine particles, depending on location (Chow et al., 1994; Duce et al., 1983; Krivacsy et al., 2001a, b). Particulate organic carbon may be either directly emitted as primary organic aerosol, or produced in the atmosphere as secondary organic aerosol (SOA) from chemical degradation of gas-phase precursors such as natural hydrocarbons (e.g. terpenes) and anthropogenic hydrocarbons

Published by Copernicus Publications on behalf of the European Geosciences Union. 
(e.g. toluene) (Seinfeld and Pandis, 1988; Kanakidou et al., 2005). Atmospheric organic species have varying degrees of polarity, with a significant fraction being water-soluble (Jacobson et al., 2000).

Inorganic particles typically experience pronounced phase transitions with varying $\mathrm{RH}$, with sudden changes from dry crystals to solution droplets and vice versa that are characterized by sharply defined points of deliquescence relative humidity (DRH) or efflorescence relative humidity (ERH). DRH and ERH are both dependent on composition and between these points the particles undergo a hysteresis in water uptake, i.e. for a specific composition and at a RH between DRH and ERH the particle can be either liquid or solid. The knowledge of the values of DRH and ERH is of great importance since, given the RH history of an air parcel they define which fraction of the atmospheric aerosol is present as purely liquid (possibly supersaturated) droplets, which as mixed-phase solid/liquid particles, and which as purely solid particles. The role of organics in the deliquescence and efflorescence behavior of inorganic aerosols is not fully understood (Cruz and Pandis, 2000; Marcolli et al., 2004) despite the importance of the physical state of such aerosols.

Conventionally, the water uptake of atmospheric particles has been associated with their inorganic fraction, while the contribution of organic aerosols has generally been neglected. However, Saxena et al. (1995) have pointed out the importance of atmospheric water-soluble organic carbon (WSOC) for the hygroscopicity of atmospheric aerosols. In addition, WSOC has been postulated to have roles similar to that of inorganics in visibility degradation and the formation of cloud condensation nuclei (Cruz and Pandis, 1998; Novakov and Penner, 1993). Although there have been measurements of the hygroscopic properties of organic salts and carboxylic acids of atmospheric relevance (Peng et al., 2001; Peng and Chan, 2001; Sjogren et al., 2007b; Gysel et al., 2004), and a number of organic species have been incorporated into a liquid phase thermodynamic model (Clegg and Seinfeld, 2006; Topping et al., 2005; Ming and Russell, 2002) there is still a need to expand our understanding using a combined approach to describe the behaviour of multicomponent mixtures of inorganic and organic compounds including potential phase separation such as through the use of LIFAC (Kiepe et al., 2006) or X-UNIFAC (Erdakos et al., 2006).

The literature on the effect of organics on the hygroscopic growth factor (HGF) of inorganic aerosols is, in general, limited and offers varying examples of their influence: some organic compounds affect the hygroscopic growth of inorganic aerosols positively and others negatively. Prenni et al. (2001) found that some dicarboxylic acids retain water to very low RH and never exhibit efflorescence. Thus, organics have, if they are sufficiently water soluble, an increasing effect on HGF below the DRH of the inorganics, and a diminishing effect above DRH (Sjogren et al., 2007b). In addition, if the organic compounds are present as surface films on aqueous droplets the mass transfer of gaseous molecules into and out of the droplet can be impeded and the hygroscopic growth factor (HGF) is reduced (Andrews and Larson, 1993; Edney et al., 2005; Hansson et al., 1998; Lightstone et al., 2000; Xiong et al., 1998). Saxena et al. (1995) found that organic compounds appeared to diminish the water uptake of inorganic compounds at urban locations, while a positive contribution was reported for a continental nonurban location. Cruz and Pandis (2000) found that glutaric acid and pinonic acid, in general, enhance water sorption of ammonium sulphate $\left(\left(\mathrm{NH}_{4}\right)_{2} \mathrm{SO}_{4}\right.$, hereinafter referred to as AS) but reduce that of $\mathrm{NaCl}$ relative to that of the pure inorganic salts. Thus, the effects of organics on inorganic aerosols appear to be species-specific. The measurements of Marcolli et al. (2004) for a range of organics and inorganics showed, in general, little influence of the organic/inorganic interactions on the water activity in mixed particles, whereas the solubility of the inorganics was clearly influenced. Also, Dick et al. (2000) found that the organic-associated water content was less than that of sulphate compounds at high relative humidity (RH) but comparable or greater at low RH.

The measured positive effect on growth due to organics is likely due to water absorption by the organics (and/or the chemical effect with the inorganics, i.e., chemical interactions between the inorganic and organic species) while observed negative effects can be either due to kinetic limitations caused by organic coatings (Xiong et al., 1998), mass transfer limitations due to inhomogeneous morphology inside the particle (Sjogren et al., 2007b), or a thermodynamic effect caused by persistent chemical interactions. The distinction between these three effects is important because organic films may not necessarily affect the water absorption of atmospheric particles at sub-saturation because of longer time scales for RH changes compared to just a few seconds applied in the traditional H-TDMA technique (Rader and McMurry, 1986; McMurry and Stolzenburg, 1989).

Choi and Chan (2002) investigated the effect of malonic and citric acid on the hygroscopic properties (water content, DRH and $\mathrm{ERH}$ ) of $\mathrm{NaCl}$ and ammonium sulphate using an electrodynamic balance (EDB). They found that at low RH $(<30 \%)$ the inorganic components in the mixed particles have crystallized, but the mixtures often contain water due to the presence of the organic species. The mixtures can then absorb water even though the $\mathrm{RH}$ is much lower than the DRH of the pure inorganic species. Again, hysteresis effects exist, and therefore prediction of the water content requires knowing the RH history of a particle. However, in the presence of organics deliquescence may occur at low RH and may easily be missed in laboratory and field hygroscopic measurements. At high RH (>80\%), particles become completely deliquesced. A big range of ambient $\mathrm{RH}$ falls between the DRH and the ERH of $\mathrm{NaCl}$ and ammonium sulphate, i.e. $\mathrm{RH}=45-80 \%$, where the effects of organics on deliquescence and efflorescence are very complex and require special attention. 
A useful technique to study the water uptake of mixed organic inorganic species is the combined Volatility and Hygroscopicity TDMA system (VH-TDMA). Briefly, the VHTDMA system operates on the same principles as a typical V-TDMA (Rader and McMurry, 1986) with the additional feature that the sample aerosol is passed through a humidified region after exiting the thermodenuder. The particle hygroscopic growth factor can then be determined as a function of the thermodenuder temperature. By increasing the temperature of the thermodenuder the more volatile species will start to evaporate from the particle (i.e. organic species are usually more volatile than inorganic sulphates) and the change in the HGF will be observed. The VH-TDMA technique was first applied in the investigation of internally mixed species and common atmospheric species (Johnson et al., 2004). Since then it has been used to study marine aerosols (Fletcher et al., 2007; Johnson et al., 2005), atmospheric iodine formation (Ristovski et al., 2006), or diesel nanoparticles (Meyer and Ristovski, 2007). The benefits of using this system are highlighted in Meyer and Ristovski (2007) where it has been shown that removal of outer layers from multi-component aerosols enables the study of internal fractions.

This paper presents an analysis of the hygroscopic properties of ammonium sulphate seeded and unseeded SOA as measured with the Hygroscopicity Tandem Differential Mobility Analyser (H-TDMA) technique. Growth factors of seeded particles were observed above and below the DRH of AS during the onset phase of the photo-oxidation experiments. The aim of this study was to characterise the relative contributions of the inorganic and organic aerosol components to the overall water uptake above and below the DRH of AS. Additional to this, combined volatility and hygroscopicity studies were conducted on seeded and unseeded particles using the VH-TDMA technique.

\section{Experimental methods}

SOA was generated via photo-oxidation of $\alpha$-pinene in a $27-\mathrm{m}^{3}$ Teflon chamber at $20^{\circ} \mathrm{C}$ and $50 \%$ relative humidity (Paulsen et al., 2005). The chamber was first humidified to $50 \% \mathrm{RH}$ before introducing $\mathrm{NO}_{\mathrm{x}}$. A known concentration of around $10 \mathrm{ppb}$ of $\alpha$-pinene (Fluka, 99.8\%) was evaporated in a heated glass sampling bulb and continuously flushed into the chamber with pure air. Four xenon arc lamps were used to simulate the solar light spectrum and initiate the photochemical reaction. Two types of chamber experiments were conducted with and without ammonium sulphate seeds. During seeded experiments ammonium sulphate was generated using an electrospray aerosol generator (TSI-3480). Ammonium sulphate was used because of its tendency to form approximately spherical seed particles (Gysel et al., 2002). This was considered important when determining total water uptake based on an increase in mobility diameter. The ability of the electrospray to generate high concentrations of

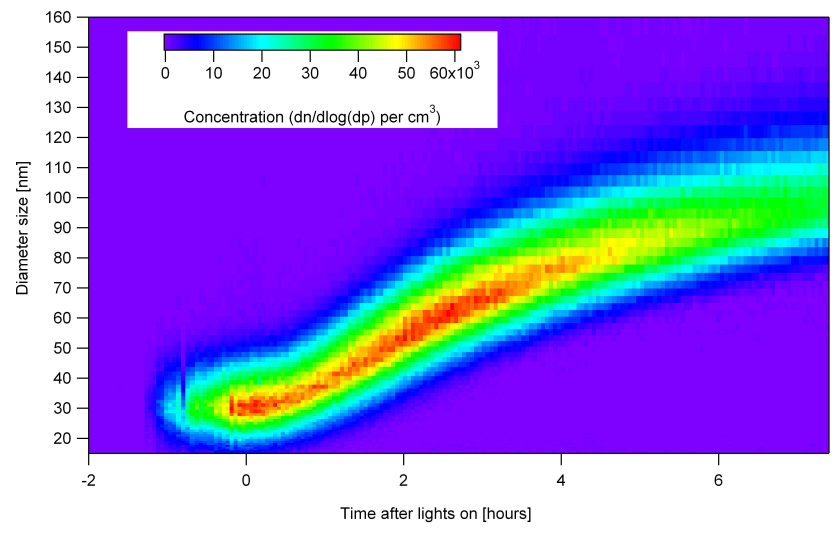

Fig. 1. Time series of size distributions measured inside the smog chamber starting with $\left(\mathrm{NH}_{4}\right)_{2} \mathrm{SO}_{4}$ seed aerosol (seed diameter of approximately $33 \mathrm{~nm}$ and $\sigma_{g}=1.3$ ) followed by the growth due to photo-oxidation of $\alpha$-pinene.

nearly mono-disperse (geom. std. dev. $\sigma_{g}=1.3$ ) aerosol particles differentiates this study from, for example, the study by (Varutbangkul et al., 2006) where poly-disperse $\left(\sigma_{g} \sim 1.75\right)$ seed samples were used. The general approach with polydisperse seed aerosol leads to mixed sizes of seed species and gives greater uncertainty in determining SOA coating thicknesses with respect to seed size. Size distribution data and number concentrations were measured using a scanning mobility particle sizer (SMPS, TSI 3080) and a condensation particle counter (CPC, TSI 3022). The SMPS performed a scan every 3 minutes while the CPC continuously measured with a $1 \mathrm{~s}$ time resolution. Chamber temperature and relative humidity were monitored using Rotronic Hygro Clip SC05 probes with an accuracy of $0.3^{\circ} \mathrm{C}$ and $1.5 \%$ respectively. Broad chemical speciation of the aerosol components in the chamber was monitored with an Aerodyne quadrupole aerosol mass spectrometer (AMS) (Canagaratna et al., 2007; Alfarra et al., 2006). Volatile and hygroscopic properties were measured with a VH-TDMA (Johnson et al., 2004).

\section{Experimental results}

A representative time series of the number size distribution measured during a seeded SOA experiment is shown as a contour plot in Fig. 1. During the hour prior to lights on, the injection of the seed particles can be noted as an increase in concentration centered around a mean diameter of $33 \mathrm{~nm}$. At time $\mathrm{t}=0 \mathrm{~h}$, the chamber is illuminated, initiating the photochemical oxidation process. As the reactions proceed, gasto-particle conversion via condensation to the seed surface occurs as the volatility of the reaction products is reduced (in the case of non-seeded experiments, this condensation phase is preceded by homogeneous nucleation of low volatility organic compounds). In all experiments, the condensation process becomes equal to the wall loss after $5 \mathrm{~h}$. From this 

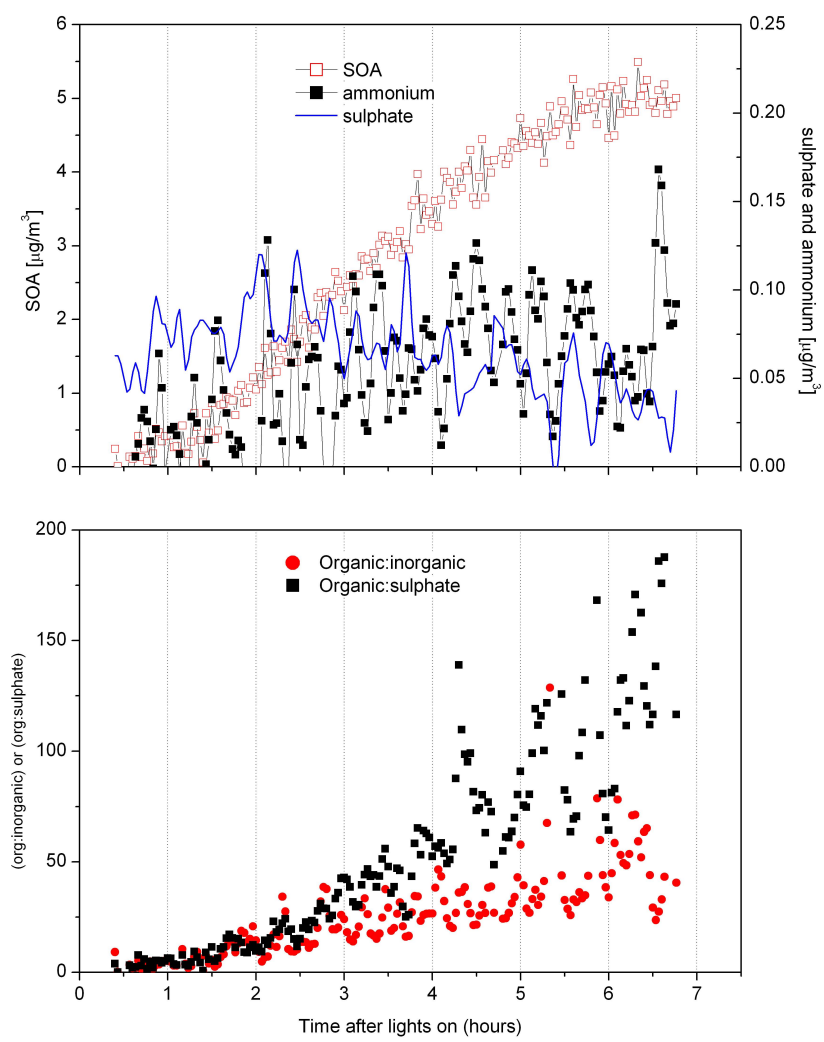

Fig. 2. Mass concentrations of organic and inorganic species in the smog chamber as measured by the AMS. The upper panel shows the mass concentrations of the sulphate, ammonium and organic species in the smog chamber during the course of the experiment. The lower shows the ratio of organic mass fraction to both the sulphate and total inorganic mass fractions during the course of the measurement period as measured by the AMS.

time onwards the total aerosol mass is constant, and after $6 \mathrm{~h}$ the total mass is decreasing (more losses than condensation). Although there was some growth after this period, our interest was in the period leading up to $6 \mathrm{~h}$ after lights on (Fig. 1). Chemical ageing processes, however, continue and become increasingly apparent when observing volatile and hygroscopic properties.

\subsection{Particle composition}

The top graph in Fig. 2 shows the temporal evolution of the AMS signal. During the onset phase of the reaction both the organic and sulphate concentrations increase. This is attributed to the condensation of the organic species on the seed surface leading to an increase in particle diameter thereby improving the transmission efficiency of the aerosol particles to the AMS (Hinz und Sprengler, 2007). After three hours however a decline in the sulphate begins due to wall losses such that by $6 \mathrm{~h}$ after lights on the sulphate mass concentration has been reduced to approximately $50 \%$ of its peak value. Within measurement uncertainties, am- monium follows the sulphate evolution. For the same period the measured organic concentration continually increases until $\sim 5 \mathrm{~h}$ after lights on. After this period our calculations show that the wall losses offset the condensational growth keeping the total mass roughly constant. Given wall losses, condensation and subsequently increasing particle diameters within the chamber it was thought that the particle detection efficiency of the AMS would increase rather than decrease. In principle, a reduction in sulphate mass could also be explained by formation of organic sulphates. Surratt et al. (2007) have recently shown the formation of ester sulphates in similar chamber measurements conducted using ammonium sulphate seeds and photo-oxidized $\alpha$-pinene and isoprene. However the formation of ester sulphates was observed to a much greater extent when the $\left(\mathrm{NH}_{4}\right)_{2} \mathrm{SO}_{4}$ seed aerosol was acidified by addition of sulphuric acid or an acidic seed aerosol was produced by photo-oxidation of $\mathrm{SO}_{2}$. Our experiments did not utilise acidic seed aerosol or $\mathrm{SO}_{2}$. Initially, this does suggest a limited likelihood of any possible reaction occurring between the organic and the sulphate and therefore in our case further investigation is required to clarify the reduction in sulphate mass. The bottom graph in Fig. 2 displays the evolution over time of the ratio of the organic to inorganic mass (solid red circles) and of the organic to sulphate mass (solid squares). In the case of the former, the inorganic fraction incorporates the sulphate and ammonium mass fractions.

\subsection{Hygroscopic properties of seeded particles}

Analysis of the hygroscopic properties of the seeded species was conducted during the onset phase of the photo-oxidation experiments. During two consecutive seeded chamber experiments the VH-TDMA was operated with the thermodenuder bypassed, therefore operating in the H-TDMA mode, at fixed relative humidities of $75 \%$ and $85 \%$, respectively. These RH's were chosen to be below and above the deliquescence relative humidity (DRH) of the pure $\left(\mathrm{NH}_{4}\right)_{2} \mathrm{SO}_{4}$ seed material. The evolution of the hygroscopic growth factor (HGF), for a $33 \mathrm{~nm}$ dry diameter particle, was measured continuously from the moment the lights in the chamber were turned on every $2 \mathrm{~min}$ for around $1.5 \mathrm{~h}$. The results for the two experiments conducted at $75 \%$ and $85 \% \mathrm{RH}$ are presented in Fig. 3.

The growth factor of the pure seed was equal to 1 at $75 \%$ $\mathrm{RH}$ as expected for any $\mathrm{RH}$ below the deliquescence point of $\left(\mathrm{NH}_{4}\right)_{2} \mathrm{SO}_{4}$. A slow increase of the HGF was initially observed after turning the lights on, followed by a strong increase to a HGF of $\sim 1.25$ approximately 30 minutes later, when the $\left(\mathrm{NH}_{4}\right)_{2} \mathrm{SO}_{4}$ to $\mathrm{SOA}$ volume ratio dropped below 0.7. Then the HGF decreased continuously until a HGF of about 1.07 was recorded after about $1.7 \mathrm{~h}$. For pure SOA particles of equal dry diameter measured in unseeded experiments after similar light exposure time growth factors of $\sim 1.05$ were exhibited (green line on the bottom graph of 

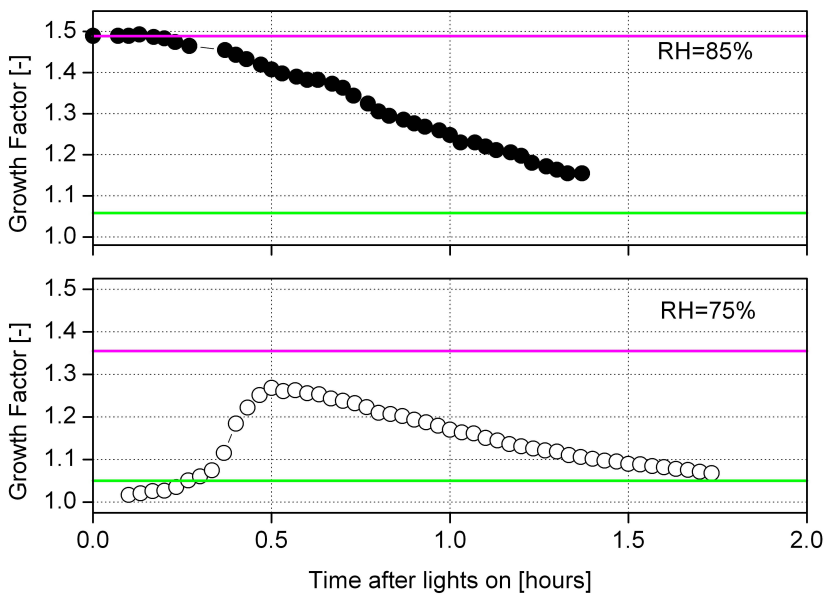

Fig. 3. Change in the hygroscopic growth factor of seeded SOA as a function of elapsed time from the moment the lights were turned on. Top graph at $\mathrm{RH}=85 \%$ (full circles) and bottom graph at $\mathrm{RH}=75 \%$ (open circles). In addition the theoretical HGF of ammonium sulphate (magenta) and the measured HGF of unseeded SOA (green) at the two different $\mathrm{RH}$ are also presented.

Fig. 3). Thus the observed maximum growth factors cannot be explained by the water uptake of the SOA only, and hence the $\left(\mathrm{NH}_{4}\right)_{2} \mathrm{SO}_{4}$ must be at least partially dissolved. It is clearly seen that the SOA enables at least a fraction of $\left(\mathrm{NH}_{4}\right)_{2} \mathrm{SO}_{4}$ to be dissolved and thus contribute to water uptake at RH's below the DRH of pure $\left(\mathrm{NH}_{4}\right)_{2} \mathrm{SO}_{4}$ (although complete dissolution of AS might still only occur at $\mathrm{RH} \geq \mathrm{DRH}$ of pure $\left.\left(\mathrm{NH}_{4}\right)_{2} \mathrm{SO}_{4}\right)$. This is in line with previous findings (Marcolli et al., 2004; Marcolli and Krieger, 2006) which show that organic compounds can increase the solubility and thus decrease the DRH of ammonium sulphate in mixed particles. To our knowledge this is the first time that SOA derived from photo-oxidised $\alpha$-pinene has been shown to affect the water uptake of inorganic aerosols below their DRH.

The samples studied at $\mathrm{RH}=85 \%$ above the DRH initially showed high $\mathrm{HGF}=1.49$ (solid black circles) in agreement with the theoretical value for a 33-nm pure ammonium sulphate particle (magenta line in Fig. 3). As the thickness of the SOA coating increased the HGF monotonically decreased towards the HGF of pure SOA (green line on Fig. 3). A reduction in the HGF of SOA containing a $\left(\mathrm{NH}_{4}\right)_{2} \mathrm{SO}_{4}$ seed aerosol has been previously observed in the ozonolysis of cycloalkenes (Varutbangkul et al., 2006) and photo-oxidation of $\alpha$-pinene, $\beta$-pinene, and limonene (Cocker III et al., 2001; Virkkula et al., 1999).

\subsection{VH-TDMA spectra of seeded and unseeded particles}

The volatile and hygroscopic properties were measured simultaneously with the VH-TDMA both for the unseeded (pure SOA) and seeded particles. The particles were heated

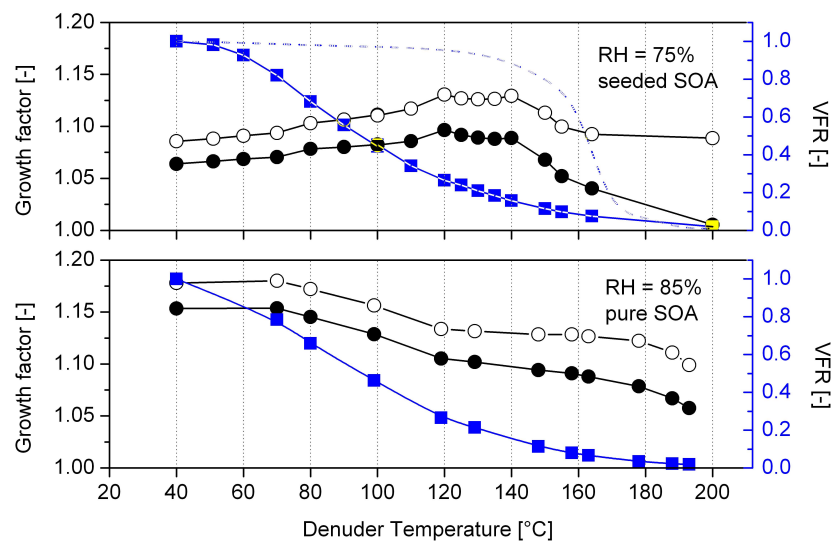

Fig. 4. Change in the hygroscopic growth factor (full circles, left $y$ axis) and volume fraction remaining (VFR) (squares, right $y$-axis) as a function of the thermodenuder temperature. These measurements were conducted after $5 \mathrm{~h}$ of measurement time had elapsed and condensation of organic species was considered to have ceased. Top graph is of 100-nm seeded particles and the bottom graph is of pure 100-nm SOA particles. In addition the HGF* (open circles) corrected for the Kelvin effect (at constant $\mathrm{a}_{w}$ ) is also presented. For comparison, on the top graph, the VFR of pure AS particles is presented with a dashed blue line.

in the thermodenuder to a temperature that was ramped from room temperature to $200^{\circ} \mathrm{C}$ in steps of 5 or $10^{\circ} \mathrm{C}$. For each thermodenuder temperature the hygroscopic growth factor was measured. The bottom graph in Fig. 4 shows the HGF at $\mathrm{RH}=85 \%$, for $100 \mathrm{~nm}$ pure SOA particles with respect to the thermodenuder temperature as well as the volume fraction remaining (VFR). In addition the HGF corrected for the Kelvin effect at $\mathrm{a}_{w}=0.85$ (HGF*; assuming surface tension of pure water) is also presented. These measurements were conducted after $5 \mathrm{~h}$ since the lights were turned on and have taken around $1 \mathrm{~h}$ for a temperature scan from room to $200^{\circ} \mathrm{C}$. During this time although there was some condensation of organic species it was not considered to be significant. Further any aging effects during the VH-TDMA scan, of $1 \mathrm{~h}$, were also negligible.

For pure SOA particles a reduction in particle diameter in response to heating results in a decrease of the HGF at constant RH due to the increasing influence of the Kelvin effect. In the absence of chemical transformation the Kelvin corrected HGF* $^{*}$ would remain constant, while for mixed particles the relative fractions of more and less hygroscopic compounds may also be altered resulting in a change of both HGF and HGF*. Here a decreasing trend of both HGF and HGF* is seen for temperatures from 70 to $115^{\circ} \mathrm{C}$. This would indicate that the volatilized compounds are more hygroscopic than the remaining material. A further increase in the thermodenuder temperatures up to $180^{\circ} \mathrm{C}$ results in a more pronounced reduction of the HGF than the Kelvin corrected one, $\mathrm{HGF}^{*}$, indicating that the reduction in the growth factor 
is more influenced by the reduction in particle size than a change in the composition. One would expect that preferential evaporation of more volatile (less hygroscopic) material occurs with increasing temperature, resulting in an increased HGF. However, the opposite is true, suggesting that the remaining aerosol has an enhanced degree of oligomerisation, resulting in larger molecules with lower HGF. It should be noted that enhanced oligomerisation could occur as a result of the increased temperature. This would mean that the VTDMA introduces an artefact, by rendering the particles less volatile than without the heating.

The top graph in Fig. 4 shows the change in HGF and HGF* of $100-\mathrm{nm}$ seeded particles measured at $75 \% \mathrm{RH}$ with respect to thermodenuder temperature. Similar to the measurements of pure SOA these measurements were also conducted $5 \mathrm{~h}$ since the lights were turned on and condensation of organic species was considered to have ceased. In contrast to the previous case we observe an increase in the HGF as the thermodenuder temperature is increased. This increase is due to the influence of the ammonium sulphate seed. As has been previously shown (see bottom graph in Fig. 3) SOA enables $\left(\mathrm{NH}_{4}\right)_{2} \mathrm{SO}_{4}$ seeds to take up water at $\mathrm{RH}$ of $75 \%$, which is below the DRH of pure AS. As the temperature is increased more of the volatile, but less hygroscopic, SOA is removed from the particles and the volume fraction of $\left(\mathrm{NH}_{4}\right)_{2} \mathrm{SO}_{4}$ increases therefore resulting in an increase of the HGF. For temperatures above $140^{\circ} \mathrm{C}\left(\mathrm{NH}_{4}\right)_{2} \mathrm{SO}_{4}$ starts to evaporate. In the temperature range from $140-165^{\circ} \mathrm{C}$ the $\mathrm{HGF}^{*}$ of pure SOA particles remains constant therefore the reduction in $\mathrm{HGF}$ of seeded particles is due to the evaporation of $\left(\mathrm{NH}_{4}\right)_{2} \mathrm{SO}_{4}$. After $170^{\circ} \mathrm{C}$ most of the $\left(\mathrm{NH}_{4}\right)_{2} \mathrm{SO}_{4}$ has evaporated and the decrease of the HGF is due to the Kelvin effect as can be seen from the constant value of the HGF*.

\section{Discussion}

The HGF of a mixed particle $\left(H G F_{m}\right)$ can be estimated from the growth factors of the individual components of the particle and their respective volume fractions, applying the ZSR relation (Stokes and Robinson, 1966) which is equivalent to:

$$
H G F_{m}=\left(\sum_{k} \varepsilon_{k} H G F_{k}^{3}\right)^{1 / 3} .
$$

where the summation is performed over all of the compounds that are present in the particle. $\varepsilon_{k}$ is the volume fraction and $H G F_{k}$ is the hygroscopic growth factor of each of the components present in the particle. The major simplifying assumption of the ZSR relationship compared to full thermodynamic models is that there are no solute-solute interactions, i.e. that the water uptake of the mixed particle is equal to the sum of the individual water uptakes of each component. Correct treatment of the Kelvin effect within the ZSR relationship means to take the $H G F_{k}$ at equal water activity as $H G F_{m}$, or in good approximation at equal $\mathrm{RH}$ and dry size as the mixed particle. The ZSR relation in the form of Eq. (1) contains additional assumptions: sphericity of the particles and no change in the volume upon mixing (ideal mixing behaviour).

In the case of a seeded SOA particle a two component system, with ammonium sulphate as one component and SOA as the other is assumed. Applying the ZSR relationship the HGF of such a mixed particle becomes:

$$
H G F_{m}=\left(\varepsilon \times H G F_{\mathrm{SOA}}^{3}+(1-\varepsilon) \times H G F_{A S}^{3}\right)^{1 / 3}
$$

where $\varepsilon$ is the volume fraction of $\mathrm{SOA} ; H G F_{\mathrm{SOA}}$ and $H G F_{A S}$ are the hygroscopic growth factors of pure SOA and ammonium sulphate. $H G F_{A S}$ is taken from ADDEM (Topping et al., 2005), whereas $H G F_{\mathrm{SOA}}$ is taken from the measurements conducted during unseeded experiments during this campaign and previous studies (Duplissy et al., 2008). It should be noted that $H G F_{\mathrm{SOA}}$ increases slightly with ongoing photooxidation (Duplissy et al., 2008). The measurements of pure SOA were usually not available at exactly equal dry size, $\mathrm{RH}$ and time after lights on. For this reason the semi-empirical $k$-Köhler theory (Petters and Kreidenweis, 2007) was used to extrapolate the original measurement to the $\mathrm{RH}$ and dry size required as input for the ZSR model. Associated uncertainties are taken into account for the error estimates of the ZSR predictions.

The volume fraction of the SOA $(\varepsilon)$ in a particle of a given dry size at a certain time was determined from the evolution of the particle number size distribution measured by the SMPS (see Fig. 1). The diameter of the seed core, $D_{\text {seed, }}$ corresponding to coated particles with diameter $D_{\text {coated }}$ at a certain time $t$ is obtained from the following implicit equation:

$$
\begin{aligned}
& \frac{1}{N_{\text {tot }}\left(t_{0}\right)} \int_{0}^{D_{\text {seed }}} \frac{d N\left(D_{p}, t_{0}\right)}{d \log D_{p}} d \log D_{p}=\frac{1}{N_{\text {tot }}(t)} \\
& \int_{0}^{D_{\text {coated }}} \frac{d N\left(D_{p}, t\right)}{d \log D_{p}} d \log D_{p},
\end{aligned}
$$

where $N_{\text {tot }}$ denotes the total number of particles. $t_{0}$ is the time at $t$ he beginning of the experiment after introducing the pure seed aerosol into the reaction chamber and before starting the photochemical reaction. The volume fraction of the $\mathrm{SOA}, \varepsilon$, becomes then:

$\varepsilon=1-\frac{D_{\text {seed }}^{3}}{D_{\text {coated }}^{3}}$

Calculating $\varepsilon$ with equations 3 and 4 contains the assumption that the percentile values of $D_{\text {seed }}$ and $D_{\text {coated }}$ in the number size distributions at time $t_{0}$ and $t$, respectively, are equal. This approach assumes that the particles don't change 


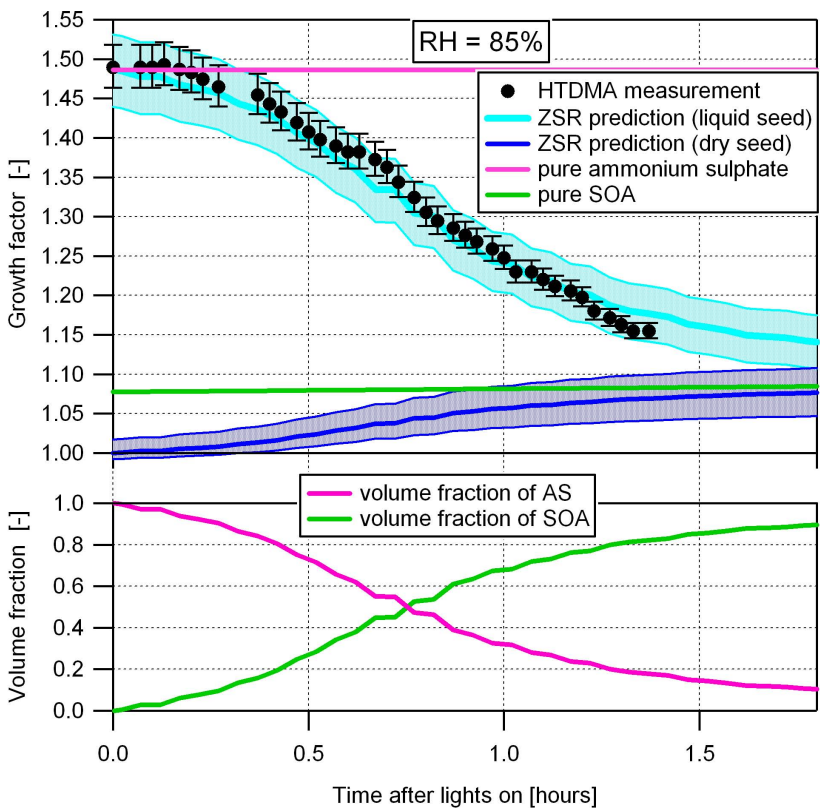

Fig. 5. Top graph: Comparison of the measured HGF (full circles) and calculated applying the ZSR relationship Eq. (2) at RH=85\%. Two calculations are shown: the first one assuming that the AS seed is fully dissolved (ZSR prediction (liquid seed)) and second under the assumption that the AS seed is not dissolved (ZSR prediction (dry seed)). The shaded band around the calculated curves illustrates the high and low estimates for a 5\% uncertainty in the SMPSderived seed diameter and a $3 \%$ uncertainty in the HGF of the pure SOA. The error bars for the measured HGF data reflect an RH accuracy of $\triangle \mathrm{RH}=1.2 \%$. A constant $H G F_{A S}$ of ammonium sulphate at $\mathrm{RH}=85 \%$ and for a dry particle size of $\mathrm{D}=28.7 \mathrm{~nm}$ was assumed (pure ammonium sulphate). The change in the $H G F_{\mathrm{SOA}}$ of SOA, for the same RH and dry particle size, was assumed to be time dependent (pure SOA). Bottom graph: The dependence of the volume fraction of SOA and AS as a function of the time since lights were turned on.

their relative order in particle diameter upon condensational growth, i.e. coagulation is ignored. The uncertainty of seed diameters determined in this way is estimated to be about $5 \%$ and is propagated through the ZSR predictions. Comparisons of the ZSR predictions with the H-TDMA measurements of the seeded SOA particles at $85 \%$ and $75 \%$ are shown in Fig. 5 and Fig. 6, respectively.

Comparison of the measured HGF at $85 \%$ relative humidity and calculated applying the ZSR relationship Eq. (2) is shown on Fig. 5 (top graph). The bottom graph in Fig. 5 shows the change of the volume fraction of SOA $(\varepsilon)$ derived from the SMPS measurements as described above, which was used for the ZSR calculations. Two types of ZSR predictions are shown: the first one assuming that the $\left(\mathrm{NH}_{4}\right)_{2} \mathrm{SO}_{4}$ seed is fully dissolved (cyan line; $H G F_{A S}=1.49$ ) and the second under assumption that the $\left(\mathrm{NH}_{4}\right)_{2} \mathrm{SO}_{4}$ seed is not dissolved (dark blue line; $H G F_{A S}=1$ ). The shaded band around the calculated curves illustrates the high and low estimates

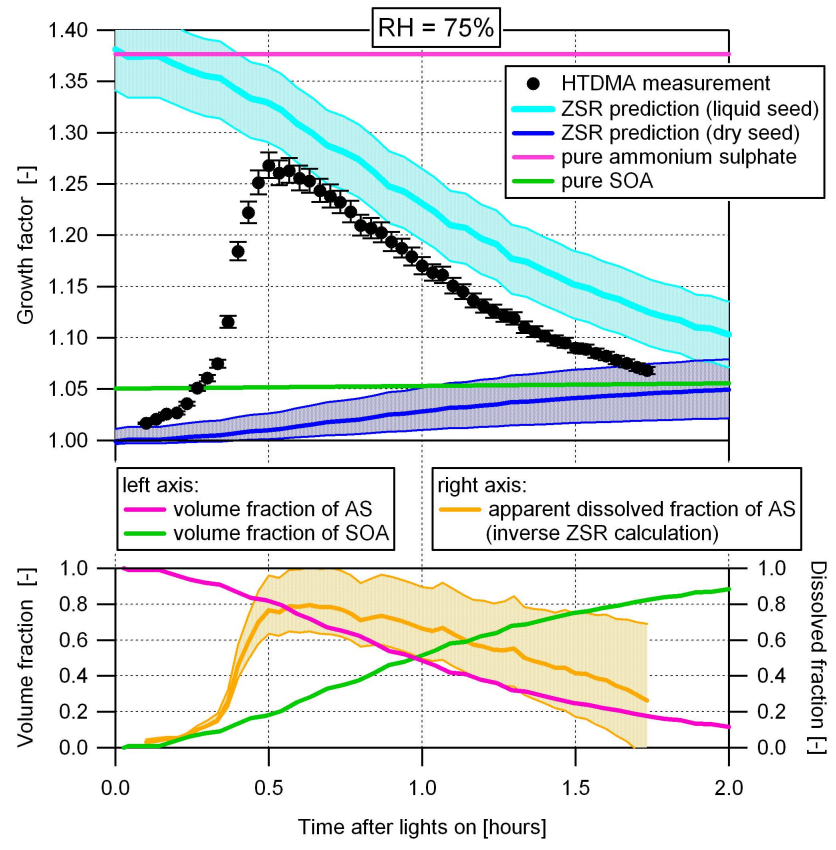

Fig. 6. The top graph shows the comparison of the measured HGF (full circles) and calculated applying the ZSR relationship Eq. (2) for $\mathrm{RH}=75 \%$. Two calculations are shown: the first one assuming that the AS seed is fully dissolved (ZSR prediction (liquid seed)) and second under the assumption that the AS seed is not dissolved (ZSR prediction (dry seed)). The shaded band around the calculated curves illustrates the high and low estimates for a 5\% uncertainty in the SMPS-derived seed diameter and a $3 \%$ uncertainty in the HGF of pure SOA. The error bars for the measured HGF data reflect an $\mathrm{RH}$ accuracy of $\triangle \mathrm{RH}=1.2 \%$. A constant $H G F_{A S}$ of ammonium sulphate at $\mathrm{RH}=75 \%$ and for a dry particle size of $\mathrm{D}=35.3 \mathrm{~nm}$ was assumed (pure ammonium sulphate). The change in the $H G F_{\text {SOA }}$ of SOA, for the same RH and dry particle size, was assumed to be time dependent (pure SOA). Bottom graph shows the change in the volume fraction of SOA (green line), AS (pink line) and the apparent dissolved fraction of AS (brown line). The apparent dissolved fraction was calculated from the ZSR relationship.

for a 5\% uncertainty in the SMPS-derived seed diameter and a $3 \%$ uncertainty in the HGF of the pure SOA. The error bars for the measured HGF data reflect an RH accuracy of $\Delta \mathrm{RH}= \pm 1.2 \%$. A good agreement between the calculated growth factor, assuming a fully dissolved seed, and measured growth factors is observed. This indicates that at $\mathrm{RH}$ of $85 \%$ the ZSR relation is accurate for this mixture, which means that there is little interaction between the organic and inorganic solutes and that they independently absorb water. This further confirms that the $\left(\mathrm{NH}_{4}\right)_{2} \mathrm{SO}_{4}$ is fully dissolved at the $\mathrm{RH}$ of $85 \%$. Similar observations of good agreement between the ZSR theory and measured HGF for mixtures of organics and inorganics at high RH, when the components have completely deliquesced, was observed previously (Choi and Chan, 2002; Cruz and Pandis, 2000; Marcolli et al., 2004). 


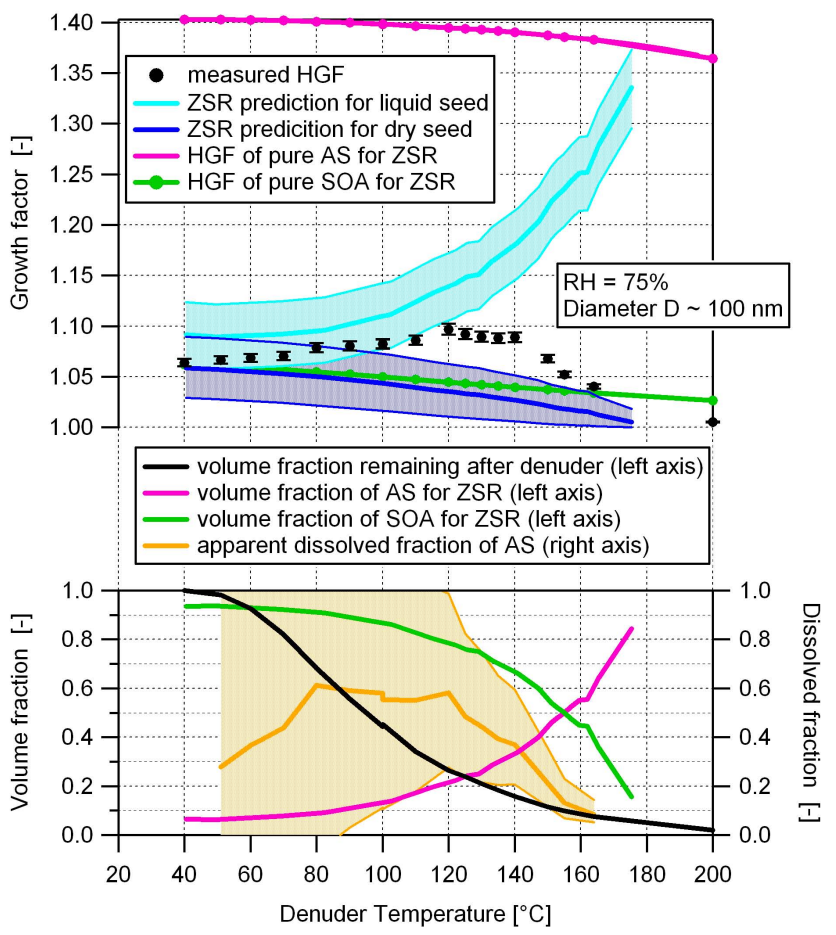

Fig. 7. Top graph: comparison between the change of the measured growth factor (full circles) and calculated applying the ZSR relationship Eq. (2) as a function of the thermodenuder temperature. Two calculations are shown: the first one assuming that the AS seed is fully dissolved (ZSR prediction for liquid seed) and second under assumption that the AS seed is not dissolved (ZSR prediction for dry seed). The shaded band around the calculated curves illustrates the high and low estimates for a 5\% uncertainty in the SMPS-derived seed diameter and a 3\% uncertainty in the HGF of pure SOA. The error bars for the measured HGF data reflect an $\mathrm{RH}$ accuracy of $\Delta \mathrm{RH}=1.2 \%$. As the particle diameter decreases with increased thermodenuder temperature a variable $H G F_{A S}$ of ammonium sulphate at $\mathrm{RH}=75 \%$, reflecting the Kelvin effect, was assumed (HGF of pure AS for ZSR). The change in the $H G F_{\mathrm{SOA}}$ of SOA, for the same RH and variable dry particle size was assumed to be time dependent (HGF of pure SOA for ZSR). Bottom graph shows change in the volume fraction remaining (black line); volume fraction of SOA (green line), AS (pink line) on the left axis and the apparent dissolved fraction of AS (brown line) on the right axis. The apparent dissolved fraction was calculated from the ZSR relationship.

Figure 6 shows a similar comparison between measurements and ZSR predictions of growth factors but this time at $\mathrm{RH}=75 \%$ and for a dry particle size of $\mathrm{D}=35.3 \mathrm{~nm}$. There are again two different ZSR predictions assuming undissolved (dark blue line) or fully dissolved $\left(\mathrm{NH}_{4}\right)_{2} \mathrm{SO}_{4}$ (cyan line; $H G F_{A S}=1.38$ ). The uncertainties were calculated in the same way as for the previous case. The volume fraction of SOA is presented in the bottom graph. There are 2 distinctive regions, where the $H G F_{m}$ first increases and later decreases. In the first region the measured $H G F_{m}$ starts off close to the "undissolved" ZSR prediction and as the volume fraction of SOA $(\varepsilon)$ increases the $H G F_{m}$ moves towards the "fully dissolved" ZSR prediction. The observed increase in the growth factor, with an increase in $\varepsilon$ is larger than what the "undissolved" ZSR prediction implies. This indicates that an increasing fraction of the $\left(\mathrm{NH}_{4}\right)_{2} \mathrm{SO}_{4}$ is in solution with an increase of the volume fraction of SOA. This is in agreement with the previous observation of Marcolli et al. (2004) where the addition of a small amount of organic species (dicarboxylic acids) has increased the solubility of $\left(\mathrm{NH}_{4}\right)_{2} \mathrm{SO}_{4}$ in the mixed particle by up to $40 \%$.

The maximum $H G F_{m}$ was observed for $\varepsilon \sim 0.3$ after $0.5 \mathrm{~h}$. A similar maximum water uptake at $\mathrm{RH}$ of $75 \%$ was also observed by Marcolli et al. (2004) for a mixture of 5 dicarboxylic acids and $\left(\mathrm{NH}_{4}\right)_{2} \mathrm{SO}_{4}$ (see Fig. 7 in Marcolli et al., 2004). The main difference is that they observed a maximum water uptake at a larger fraction of organics of $50 \mathrm{wt} \%$ while we observed a maximum water uptake at around $20 \mathrm{wt} \%$ (under the assumption that the SOA density is $1.3 \mathrm{~g} / \mathrm{cm}^{3}$ (Varutbangkul et al., 2006; Alfarra et al., 2006) and the AS density is $1.77 \mathrm{~g} / \mathrm{cm}^{3}$ ).

After this time the measured growth factor follows roughly parallel to the ZSR prediction based on fully dissolved $\left(\mathrm{NH}_{4}\right)_{2} \mathrm{SO}_{4}$. It is important to note that there is a difference between the calculated and measured growth factors which is just larger than the error estimate.

There are several possible reasons for over prediction of $H G F_{m}$ with the ZSR approach assuming fully dissolved $\left(\mathrm{NH}_{4}\right)_{2} \mathrm{SO}_{4}$. The first to consider would be that there are kinetic limitations such that the equilibrium $\mathrm{RH}$ is not reached in the instrument for the time the particles are exposed to high humidity (which is around $2 \mathrm{~s}$ in the $\mathrm{RH}$ conditioner and an additional $3 \mathrm{~s}$ in the $H$-DMA). The mass transfer analysis for submicron particles (Kerminen, 1997) shows that the required time to achieve equilibrium is less than the times experienced in our system. On the other side if organic coatings, such as in our case, are present on the particles it has been suggested that they may reduce the rate of water transport across the surface by acting as a physical barrier (Chuang, 2003; Xiong et al., 1998; Johnson et al., 2005). If insufficient time is allowed for particles to achieve their final size a lower HGF will be measured. However it is not likely that there were kinetic limitations in the measurements at RH of $75 \%$ as we would have observed similar effects at $\mathrm{RH}$ of $85 \%$. As discussed previously measurements at RH of $85 \%$ show good agreement with the ZSR prediction.

A second possible reason could be then that the $\left(\mathrm{NH}_{4}\right)_{2} \mathrm{SO}_{4}$ seed was not completely dissolved. Let us now calculate the apparent dissolved fraction of $\left(\mathrm{NH}_{4}\right)_{2} \mathrm{SO}_{4}$. SOA produced by photo-oxidation of $\alpha$-pinene exhibits a continuous water uptake even at very low RH's (Duplissy et al., 2008; Varutbangkul et al., 2006) therefore we can assume that at $\mathrm{RH}=75 \%$ SOA is fully dissolved. If SOA is fully dissolved and AS is partially dissolved the hygroscopic growth factor can then be calculated as: 


$$
\begin{aligned}
& H G F_{m}=\left(\varepsilon_{\mathrm{SOA}} \times H G F_{\mathrm{SOA}}^{3}+\varepsilon_{\mathrm{DAS}}\left(1-\varepsilon_{\mathrm{SOA}}\right) \times\right. \\
& \left.H G F_{A S}^{3}+\left(1-\varepsilon_{\mathrm{DAS}}\right)\left(1-\varepsilon_{\mathrm{SOA}}\right) \times 1\right)^{1 / 3}
\end{aligned}
$$

Where $H G F_{\text {SOA }}$ is the growth factor of fully dissolved SOA with a volume fraction of $\varepsilon_{\mathrm{SOA}} ; H G F_{A S}=1.38$ is the growth factor of pure AS (at $\mathrm{RH}=75 \%$ ) and $\varepsilon_{\mathrm{DAS}}$ the apparent dissolved volume fraction of AS. From the measured $H G F_{m}$ and knowing the volume fraction of SOA $\left(\varepsilon_{\mathrm{SOA}}\right)$ as well as the $H G F_{\text {SOA }}$ it is possible to calculate $\varepsilon_{\mathrm{DAS}}$ from Eq. (5). Note that $\varepsilon_{\text {DAS }}$ used in Eq. (5) is the ratio of the volume of dissolved AS to the total volume of AS present in the particle. The calculated $\varepsilon_{\text {DAS }}$ is presented on the bottom graph (right axis) of Fig. 6. The coloured band around the line representing the apparent dissolved volume fraction presents the overall uncertainty arising from the uncertainties of $\varepsilon_{S O A}, H G F_{\mathrm{SOA}}$, and $H G F_{m}$, as already introduced above.

As the volume fraction of SOA increases so does the $\varepsilon_{\text {DAS }}$ of AS until it reaches a maximum of around $80 \%$ for $\varepsilon_{\mathrm{SOA}} \approx 0.3$. For larger values of $\varepsilon_{\mathrm{SOA}}$ the $\varepsilon_{\mathrm{DAS}}$ decreases though this trend is not significant regarding the large uncertainty. The initial increase in $\varepsilon_{\text {DAS }}$ is similar to what would be expected from binary salt mixed solutions (see discussion on p. 517, Seinfeld and Pandis, 1998). Seinfeld and Pandis (1998) discuss the changes in a particle of a given composition as RH is increased. Let us discuss a slightly different case, which corresponds to our situation, where the composition of a binary mixture of two electrolytes at a constant RH is changed. Marcolli et al. (2004) estimated that the DRH of the eutonic composition of five dicarboxylic acids and ammonium sulphate was below $40 \%$. Hence we can assume that at $\mathrm{RH}=75 \%$ we are between the DRH of the component with a higher DRH (AS) and the DRH of the eutonic composition. Initially we have pure AS and the particle is solid. Addition of SOA causes the particle to consist of two phases: a solid phase consisting of pure AS and an aqueous solution of SOA and AS. The composition of the aqueous solution corresponds to the composition of a mixed particle that would deliquesce at $\mathrm{RH}$ of $75 \%$. All of the SOA that is added to the particle goes into solution. As the composition of the aqueous solution has to remain constant at a constant RH this will cause more AS to be dissolved. Once the particle composition becomes equal to the composition of the particle that will deliquesce at $\mathrm{RH}$ of $75 \%$ all of the AS should have been dissolved and the particle should have only one phase-liquid.

As mentioned previously our calculations show that AS is never fully dissolved and reaches a maximum value of $80 \%$. A possible reason for the apparent dissolved fraction to be smaller than unity could be due to negative solute-solute interactions between SOA and AS. Topping et al. (2005) applied the ADDEM model to the results of Marcolli et al. (2004) where they studied the water activity of a multicomponent organic mixture (5 components) with a single in- organic salt. They showed that at higher relative humidity, when the solutions are more dilute, the additive approximation works very well. This means that the interaction between the organic and inorganic fractions is not as strong as in more concentrated solutions. In the case of the AS-organic system that they analysed, the deviations increase with decreasing relative humidity, i.e., more concentrated solutions. The model tends to over predict the observed water content which indicates that the organic-inorganic interactions lead to negative contributions to the total water content for AS. This agrees well with our experimental observation where the measurements at $\mathrm{RH}$ of $85 \%$ agree well with the additive approximation (ZSR theory - no interactions between $\mathrm{AS}$ and SOA) while for the measurements at RH of $75 \%$, the interaction is negative leading to a smaller HGF than predicted by the ZSR theory.

We also compared the calculated HGF's using the ZSR relationship for the VH-TDMA measurements conducted on seeded 100-nm particles (previously presented on the top graph of Fig. 4). This comparison is now presented on the top graph of Fig. 7. Same as before two calculations are shown with a fully dissolved AS seed and under assumption that the AS seed is not dissolved. As the particle diameter reduces with increased thermodenuder temperature a variable $H G F_{A S}$ of pure ammonium sulphate at $\mathrm{RH}=75 \%$, reflecting the Kelvin effect, had to be used as input for the ZSR calculations. To calculate the $H G F_{\mathrm{SOA}}$ of SOA for different thermodenuder temperatures, measurements conducted with pure (unseeded) SOA particles were used (see bottom graph on Fig. 4) and extrapolated to correct RH and dry size using the k-Köhler theory (Petters and Kreidenweis, 2007; Sjogren et al., 2007a).

A similar situation is observed for the VH-TDMA measurement as in the H-TDMA measurements conducted at RH of $75 \%$ shown on Fig. 6 . There, the SOA coating thickness increased with time, while for the case presented in Fig. 7 the SOA coating thickness was reduced by passing it through a thermodenuder at an elevated temperature (note that the SOA volume fraction is being reduced as the temperature is increased from left to right which is opposite to the situation shown on Fig. 6, where the SOA volume fraction is increased as time passes going from left to right). We have also calculated the apparent dissolved volume fraction of AS $\left(\varepsilon_{\mathrm{DAS}}\right)$ from Eq. (5). This is presented on the bottom graph (right axis) of Fig. 7. In this case the maximum apparent dissolved fraction of AS was around $60 \%$ although the uncertainties involved in these calculations were much larger than in the previous case. This also points out to incomplete dissolution of AS or negative solute-solute interactions due to the more concentrated solutions at $75 \% \mathrm{RH}$. 


\section{Conclusions}

The hygroscopic and volatile properties of SOA formed by photo-oxidation of $\alpha$-pinene were studied. Two types of chamber experiments were conducted with and without ammonium sulphate seeds. The combined measurements of the volatile and hygroscopic properties of pure, unseeded, SOA were measured with a VH-TDMA. They show a decrease in the $\mathrm{HGF}$ for thermodenuder temperatures from 70 to $115^{\circ} \mathrm{C}$ that is larger than the expected decrease due to the Kelvin effect. This indicates that the compounds that are volatilised in this temperature range are more hygroscopic than the remaining material. This is opposite to the expected preferential evaporation of more volatile but less hygroscopic material that should have resulted in the increase in the HGF. However, this result could also be explained by enhanced oligomerisation occurring at the higher temperature in the thermodenuder.

Hygroscopic growth factors of SOA seeded with AS were measured below (RH 75\%) and above (RH 85\%) the deliquescence relative humidity of AS. The nearly monodisperse AS seeds used in this study enabled us to calculate the SOA thickness with smaller uncertainty compared to the previous studies. This enabled measurements of the dependence of the HGF at two different humidities as a function of the volume fraction of the SOA coating. As has been seen previously the HGF at RH of $85 \%$ shows a continuous decrease as the SOA coating thickness increases. The measured growth factors show good agreement with the ZSR relationship indicating that the additive approach could be used and that solute-solute interactions have a minor influence on the HGF of mixed SOA-AS particles at these humidities.

At $75 \%$ RH the observed change was more complex and showed a strong dependence on the SOA volume fraction. As the SOA fraction increased a rapid increase in the HGF was observed indicating an increasing fraction of AS in solution. This shows that the SOA coating, produced from the photo-oxidation of $\alpha$-pinene, enables at least partial dissolution of ammonium sulphate at RH below its deliquescence point in pure form. A maximum HGF was observed for a $30 \%$ volume fraction of SOA. At this SOA fraction the calculated apparent dissolved fraction of AS did not reach unity but was at a maximum value of 0.8. A further increase in the SOA fraction had a small influence on the apparent dissolved fraction of AS, with any observed change within the measurement error. Both incomplete dissolution of AS or negative solute-solute interactions could be responsible for an apparent dissolved fraction smaller than unity.

The implication of our findings on the atmospheric aerosols is that the presence of SOA coating will enhance the water uptake of the inorganic seeds at RH's lower than the DRH of the inorganic component. This also indicates that at the RH relevant to the atmospheric conditions SOA coatings could broaden the range over which particle bound water influences the physicochemical and optical properties of organic/inorganic mixed particles.

Acknowledgements. This work was supported by the EC projects ACCENT and EUROCHAMP, the European Science Foundation project INTROP as well as the Swiss National Science Foundation. We also thank René Richter and Günther Wehrle at PSI for their technical support.

Edited by: K. Hämeri

\section{References}

Alfarra, M. R., Paulsen, D., Gysel, M., Garforth, A. A., Dommen, J., Prevot, A. S. H., Worsnop, D. R., Baltensperger, U., and Coe, H.: A mass spectrometric study of secondary organic aerosols formed from the photooxidation of anthropogenic and biogenic precursors in a reaction chamber., Atmos. Chem. Phys., 6, 5279 5293, 2006, http://www.atmos-chem-phys.net/6/5279/2006/.

Andrews, E. and Larson, S. M.: Effect of surfactant layers on the size changes of aerosol particles as a function of relative humidity, Environ. Sci. Technol., 27, 857-865, 1993.

Canagaratna, M. R., Jayne, J. T., Jimenez, J. L., Allan, J. D., Alfarra, M. R., Zhang, Q., Onasch, T. B., Drewnick, F., Coe, H., Middlebrook, A., Delia, A., Williams, L. R., Trimborn, A. M., Northway, M. J., Kolb, C. E., Davidovits, P., and Worsnop, D. R.: Chemical and microphysical characterization of ambient aerosols with the aerosol mass spectrometer, Mass. Spectrom. Rev., 26, 185-222, 2007.

Choi, M. Y. and Chan, C. K.: The effects of organic species on the hygroscopic behaviors of inorganic aerosols, Environ. Sci. Technol., 36, 2422-2428, 2002.

Chow, J. C., Watson, J. G., Fujita, E. M., Lu, Z. Q., Lawson, D. R., and Ashbaugh, L. L.: Temporal and spatial variations of $\operatorname{PM}(2.5)$ and $\operatorname{PM}(10)$ aerosol in the Southern California AirQuality Study, Atmos. Environ., 28, 2061-2080, 1994.

Chuang, P. Y.: Measurement of the time scale of hygroscopic growth for atmospheric aerosols, J. Geophys. Res. D, Atmosphere, 108, 4282, doi:10.1029/2002JD002757, 2003.

Clegg, S. L. and Seinfeld, J. H.: Thermodynamic models of aqueous solutions containing inorganic electrolytes and dicarboxylic acids at 298.15 K. 2. Systems including dissociation function equilibria, J. Phys. Chem, 110, 5718-5734, 2006.

Cocker III, D. R., Clegg, S. L., Flagan, R. C., and Seinfeld, J. H.: The effect of water on gas-particle partitioning of secondary organic aerosol. Part I: [alpha]-pinene/ozone system, Atmos. Environ., 35, 6049-6072, 2001.

Cruz, C. N. and Pandis, S. N.: The effect of organic coatings on the cloud condensation nuclei activation of inorganic atmospheric aerosol, J. Geophys. Res., 103, 13111-13123, 1998

Cruz, C. N. and Pandis, S. N.: Deliquescence and hygroscopic growth of mixed inorganic-organic atmospheric aerosol, Environ. Sci. Technol., 34, 4313-4319, 2000.

Dick, W. D., Saxena, P., and McMurry, P. H.: Estimation of water uptake by organic compounds in submicron aerosols measured during the southeastern aerosol and visibility study, J. Geophys. Res, 105, 1471-1479, 2000.

Duce, R. A., Mohnen, V. A., Zimmerman, P. R., Grosjean, D., Cautreels, W., Chatfield, R., Jaenicke, R., Ogren, J. A., Pelliz- 
zari, E. D., and Wallace, G. T.: Organic material in the global troposphere, Geophys. Rev., 21, 921-952, 1983.

Duplissy, J., Gysel, M., Alfarra, M. R., Dommen, J., Metzger, A., Prevot, A. S. H., Weingartner, E., Laaksonen, A., Raatikainen, T., Good, N., Turner, S. F., McFiggans, G., and Baltensperger, U.: The cloud forming potential of secondary organic aerosol under near atmospheric conditions, Geophys, Res. Lett., 35, L03818, doi:10.1029/2007GL031075, 2008.

Edney, E. O., Kleindienst, T. E., Jaoui, M., Lewandowski, M., Offenberg, J. H., Wang, W., and Claeys, M.: Formation of 2-methyl tetrols and 2-methylglyceric acid in secondary organic aerosol from laboratory irradiated isoprene/ $\mathrm{NO}_{\mathrm{x}} / \mathrm{SO} 2 /$ air mixtures and their detection in ambient $\mathrm{PM}_{2} .5$ samples collected in the eastern United States, Atmos. Environ., 39, 5281-5289, 2005.

Erdakos, G. B., Chang, E. I., Pankow, J. F., and Seinfeld, J. H.: Prediction of activity coefficients in liquid aerosol particles containing organic compounds, dissolved inorganic salts, and water - Part 3: Organic compounds, water, and ionic constituents by consideration of short-, mid-, and long-range effects using XUNIFAC.3, Atmos. Environ., 40, 6437-6452, 2006.

Fletcher, C. A., Johnson, G. R., Ristovski, Z. D., and Harvey, M.: Hygroscopic and volatile properties of marine aerosol, observed at Cape Grim during the P2P campaign, Environ. Chem., 4, 162171, 2007.

Gysel, M., Weingartner, E., and Baltensperger, U.: Hygroscopicity of aerosol particles at low temperatures. 2. Theoretical and experimental hygroscopic properties of laboratory generated aerosols, Environ. Sci. Technol., 36, 63-68, 2002.

Gysel, M., Weingartner, E., Nyeki, S., Paulsen, D., Baltensperger, U., Galambos, I., and Kiss, G.: Hygroscopic properties of water-soluble matter and humic-like organics in atmospheric fine aerosol Atmos. Chem. Phys., 4, 35-50, 2004, http://www.atmos-chem-phys.net/4/35/2004/.

Hansson, H. C., Rood, M. J., Koloutsou Vakakis, S., Hameri, K., Orsini, D., and Wiedensohler, A.: $\mathrm{NaCl}$ aerosol particle hygroscopicity dependence on mixing with organic compounds, J. Atmos. Chem., 31, 321-346, 1998.

Hinz, K. P. and Spengler, B.: Instrumentation, data evaluation and quantification in on-line aerosol mass spectrometry, J. Mass Spectrometry, 42, 843-860, 2007.

Jacobson, M. C., Hansson, H. C., Noone, K. J., and Charlson, R. J.: Organic atmospheric aerosols: Review and state of the science, Rev. Geophys, 38, 267-294, 2000.

Johnson, G., Ristovski, Z., and Morawska, L.: Method for measuring the hygroscopic behaviour of lower volatility fractions in an internally mixed aerosol, J. Aerosol Sci., 35, 443-455, 2004.

Johnson, G. R., Ristovski, Z. D., D’Anna, B., and Morawska, L.: Hygroscopic behavior of partially volatilized coastal marine aerosols using the volatilization and humidification tandem differential mobility analyzer technique, J. Geophys. Res., 110, D20203, 2005.

Kanakidou, M., Seinfeld, J. H., Pandis, S. N., Barnes, I., Dentener, F. J., Facchini, M. C., Van Dingenen, R., Ervens, B., Nenes, A., Nielsen, C. J., Swietlicki, E., Putaud, J. P., Balkanski, Y., Fuzzi, S., Horth, J., Moortgat, G. K., Winterhalter, R., Myhre, C. E. L., Tsigaridis, K., Vignati, E., Stephanou, E. G., and Wilson, J.: Organic aerosol and global climate modelling: A review, Atmos. Chem. Phys., 5, 1053-1123, 2005,

http://www.atmos-chem-phys.net/5/1053/2005/.
Kerminen, V. M.: The effects of particle chemical character and atmospheric processes on particle hygroscopic properties, J. Aerosol Sci., 28, 121-132, 1997.

Kiepe, J., Noll, O., and J., G.: Modified LIQUAC and modified LIFAC - a further development of electrolyte models for the reliable prediction of phase equilibria with strong electrolytes, Ind. Eng. Chem. Res., 45, 2361-2373, 2006.

Krivacsy, Z., Gelencser, A., Kiss, G., Meszaros, G., Molnar, A., Hoffer, A., Meszaros, T., Sarvari, Z., Temesi, D., Varga, B., Baltensperger, U., Nyeki, S., and Weingartner, E.: Study on the chemical character of water soluble organic compounds in fine atmospheric aerosol at the Jungfraujoch, J. Atmos. Chem., 39, 235-259, 2001a.

Krivacsy, Z., Hoffer, A., Sarvari, Z., Temesi, D., Baltensperger, U., Nyeki, S., Weingartner, E., Kleefeld, S., and Jennings, S. G.: Role of organic and black carbon in the chemical composition of atmospheric aerosol at European background sites, Atmos. Environ., 35, 6233-6244, 2001b.

Lightstone, J. M., Onasch, T. B., Imre, D., and Oatis, S.: Deliquescence, efflorescence, and water activity in ammonium nitrate and mixed ammonium nitrate/succinic acid microparticles, J. Phys. Chem., 104, 9337-9346, 2000.

Marcolli, C., Luo, B., and Peter, T.: Mixing of organic aerosol fractions: Liquids as thermodynamically stable phases, J. Phys. Chem. A, 108, 2216-2224, 2004.

Marcolli, C. and Krieger, U. K.: Phase changes during hygroscopic cycles of mixed organic/inorganic model systems of tropospheric aerosols, J. Phys. Chem. A, 110, 1881-1893, 2006.

McMurry, P. H. and Stolzenburg, M. R.: On the sensitivity of particle size to relative humidity for Los Angeles aerosols., Atmos. Environ., 23, 497-507, 1989.

Meyer, N. K. and Ristovski, Z. D.: Ternary nucleation as a mechanism for the production of diesel nanoparticles: Experimental analysis of the volatile and hygroscopic properties of diesel exhaust using the volatilization and humidification tandem differential mobility analyzer, Environ. Sci. Technol., 41, 7309-7314, 2007.

Ming, Y. and Russell, L. M.: Thermodynamic equilibrium of organic-electrolyte mixtures in aerosol particles, Environmental and Energy Engineering, 48, 1331-1348, 2002.

Novakov, T. and Penner, J. E.: Large contribution of organic aerosols to cloud-condensation-nuclei concentrations, Nature, 365, 823-826, 1993.

Paulsen, D., Dommen, J., Kalberer, M., Prevot, A. S. H., Richter, R., Sax, M., Steinbacher, M., Weingartner, E., and Baltensperger, U.: Secondary organic aerosol formation by irradiation of $1,3,5$ trimethylbenzene- $\mathrm{NO}_{\mathrm{x}}-\mathrm{H}_{2} \mathrm{O}$ in a new reaction chamber for atmospheric chemistry and physics, Environ. Sci. Technol., 39, 2668-2678, 2005.

Peng, C., Chan, M. N., and Chan, C. K.: The hygroscopic properties of dicarboxylic and multifunctional acids: Measurements and unifac predictions, Environ. Sci. Technol., 35, 4495-4501, 2001.

Peng, C. G. and Chan, C. K.: The water cycles of water-soluble organic salts of atmospheric importance, Atmos. Environ., 35, 1183-1192, 2001.

Petters, M. D. and Kreidenweis, S. M.: A single parameter representation of hygroscopic growth and cloud condensation nucleus activity, Atmos. Chem. Phys., 7, 1961-1971, 2007, 
http://www.atmos-chem-phys.net/7/1961/2007/.

Prenni, A. J., DeMott, P. J., Kreidenweis, S. M., Sherman, D. E., Russell, L. M., and Ming, Y.: The effects of low molecular weight dicarboxylic acids on cloud formation, J. Phys. Chem. A, 105, 11240-11248, 2001.

Rader, D. J. and McMurry, P. H.: Application of the tandem differential mobility analyzer to studies of droplet growth or evaporation, J. Aerosol Sci., 17, 771-787, 1986.

Ristovski, Z. D., Fletcher, C., D’Anna, B., Johnson, G. R., and Bostrom, J. T.: Characterization of iodine particles with volatilization-humidification tandem differential mobility analyser (VH-TDMA), Raman and Sem techniques, Atmos. Chem. Phys. Discuss., 1481-1508, 2006.

Saxena, P., Hildeman, L. H., McMurry, P. H., and Seinfeld, J. H.: Organics alter hygroscopic behavior of atmospheric particles, J. Geophys. Res, 100, 18755-18770, 1995.

Seinfeld, J. H. and Pandis, S. N.: Atmospheric chemistry and physics: From air pollution to climate change, 2nd ed., Wiley, Hoboken, NJ, USA, 1203 pp., 2006.

Sjogren, S., Gysel, M., Weingartner, E., Alfarra, M. R., Duplissy, J., Cozic, J., Crosier, J., Coe, H., and Baltensperger, U.: Hygroscopicity ofthe submicrometer aerosol at the high-alpine site jungfraujoch, $3850 \mathrm{~m}$ a.s.l., Switzerland, Atmos. Chem. Phys. Discuss., 7, 13699-13732, 2007a, http://www.atmos-chem-phys-discuss.net/7/13699/2007/.

Sjogren, S., Gysel, M., Weingartner, E., Baltensperger, U., Cubison, M. J., Coe, H., Zardini, A. A., Marcolli, C., Krieger, U. K., and Peter, T.: Hygroscopic growth and water uptake kinetics of twophase aerosol particles consisting of ammonium sulfate, adipic and humic acid mixtures, J. Aerosol Sci., 38, 157-171, $2007 \mathrm{~b}$.
Stokes, R. H. and Robinson, R. A.: Interactions in aqueous nonelectrolyte solutions. I. Solute solvent equilibria, J. Phys. Chem, 70, 2126-2130, 1966.

Surratt, J. D., Kroll, J. H., Kleindienst, T. E., Edney, E. O., Claeys, M., Sorooshian, A., Ng, N. L., Offenberg, J. H., Lewandowski, M., Jaoui, M., Flagan, R. C., and Seinfeld, J. H.: Evidence for organosulfates in secondary organic aerosol, Environ. Sci. Technol., 41, 517-527, 2007.

Topping, D. O., McFiggans, G. B., and Coe, H.: A curved multicomponent aerosol hygroscopicity model framework: Part 2 including organic compounds, Atmos. Chem. Phys., 5, 12231242, 2005, http://www.atmos-chem-phys.net/5/1223/2005/.

Varutbangkul, V., Brechtel, F. J., Bahreini, R., Ng, N. L., Keywood, M. D., Kroll, J. H., Flagan, R. C., Seinfeld, J. H., Lee, A., and Goldstein, A. H.: Hygroscopicity of secondary organic aerosols formed by oxidation of cycloalkenes, monoterpenes, sesquiterpenes, and related compounds, Atmos. Chem. Phys., 6, 23672388, 2006, http://www.atmos-chem-phys.net/6/2367/2006/.

Virkkula, A., Van Dingenen, R., Raes, F., and Hjorth, J.: Hygroscopic properties of aerosol formed by oxidation of limonene, alpha-pinene, and beta-pinene, J. Geophys. Res.-Atmos., 104, 3569-3579, 1999.

Xiong, J. Q., Zhong, M. H., Fang, C. P., Chen, L. C., and Lippmann, M.: Influence of organic films on the hygroscopicity of ultrafine sulfuric acid aerosol, Environ. Sci. Technol., 32, 35363541, 1998. 